\title{
Vitrification of mouse embryo-derived ICM cells: a tool for preserving embryonic stem cell potential?
}

\author{
Nina Desai • Jing Xu • Tamara Tsulaia • \\ Julia Szeptycki-Lawson • Faten AbdelHafez • \\ James Goldfarb • Tommaso Falcone
}

Received: 23 August 2010 / Accepted: 18 October 2010/Published online: 6 November 2010

(C) The Author(s) 2010. This article is published with open access at Springerlink.com

\begin{abstract}
Purpose Vitrification technology presents new opportunities for preservation of embryo derived stem cells without first establishing a viable ESC line. This study tests the feasibility of cryopreserving ICM cells using vitrification. Materials and Methods ICMs from mouse embryos were isolated and vitrified in HSV straws or on cryoloops. Upon warming, the vitrified ICMs were cultured and observed for attachment and morphology. Colonies were passaged every 3-6 days. ICMs and ICM-derived ESC colonies were tested for expression of stem cell specific markers.

Results ICMs vitrified on both the cryoloop and the HSV straw had high survival rates. ICM derived ESCs remained undifferentiated for several passages and demonstrated expression of typical stem cell markers; SSEA-1, Sox-2, Oct 4 and alkaline phosphatase.

Conclusion This is the first report on successful vitrification of isolated ICMs and the subsequent derivation of ESC colonies. Vitrification of isolated ICMs is a novel approach for preservation of the "stem cell source" material.
\end{abstract}

Financial support: None

Capsule Vitrification of isolated ICMs is a novel approach for preservation of the "stem cell source" material.

N. Desai $\cdot$ J. Xu $\cdot$ T. Tsulaia $\cdot$ J. Szeptycki-Lawson

F. AbdelHafez $\cdot$ J. Goldfarb $\cdot$ T. Falcone

Department of OB-GYN, Cleveland Clinic Foundation,

Women's Health Institute,

Beachwood, OH, USA

N. Desai $(\bowtie)$

The Cleveland Clinic Fertility Center,

26900 Cedar Rd,

Beachwood, OH 44122, USA

e-mail: desain@ccf.org
Keywords Blastocyst · Cryopreservation · Human embryonic stem cells $\cdot$ Inner cell mass $\cdot$ Vitrification

\section{Introduction}

Embryonic stem cell (ESC) lines are derived from the inner cell mass (ICM) of blastocysts, and the defining feature of these cells is their ability to differentiate into a variety of cell types that encompass all three embryonic germ layers [1]. Pluripotent cell lines were first generated from mouse blastocysts in 1981 [2]. Thomson and colleagues subsequently demonstrated successful derivation of embryonic stem cells from human blastocysts [3]. Embryonic stem cells, particularly human stem cells hold tremendous potential in the field of regenerative medicine, in addition to being a useful tool in basic scientific research and for pharmacological and cytotoxicity screening $[4,5]$.

Methods for efficient and reliable preservation of embryonic stem cells are necessary to preserve these pluripotent cells for therapeutic and experimental use. The traditional method for embryonic stem cell cryopreservation has been slow cooling at rates of approximately $-1^{\circ} \mathrm{C}$ per minute [reviewed in [6]]. Recently, cryopreservation by vitrification has received much attention. This technique has been successfully applied to the cryopreservation of embryos at a variety of stages [7-12] as well as oocytes [13-15]. Vitrification involves ultra-rapid cooling of the cell at rates as high as $-20,000^{\circ} \mathrm{C} / \mathrm{min}$ and the use of high concentrations of cryoprotectant agents (CPA). To achieve these high cooling rates the cell is frozen in miniscule volumes of fluid in vessels that allow almost instantaneous cooling to $-196^{\circ} \mathrm{C}$. Vitrification protocols have also been successfully used for cryopreservation of human embryonic stem cell lines $[16,17]$. Numerous publications suggest that 
cell preservation by vitrification may be superior to slow cooling methodologies [18] [reviewed in [19, 20]].

To date there have been no reports on the cryopreservation of ICM cells extracted from the blastocyst stage embryo. Preservation of isolated embryo-derived stem cells without first establishing a viable ES cell line offers a new avenue for banking the stem cell source material. The small number of cells in the ICM of Day 5 or Day 6 blastocysts poses a special challenge during the cryopreservation process. In this investigation we explore the feasibility of ICM vitrification and subsequent establishment of ESC-like colonies. ICM isolation methodology and its influence on cryosurvival and subsequent retention of ES phenotype were looked at.

\section{Materials and methods}

\section{ICM isolation}

Mouse one-cell zygotes (Charles River Laboratory; Wilmington, MA) were used for all ICM isolation experiments. The zygotes were thawed as per manufacturer's instructions and cultured overnight in Global Blastocyst medium (LifeGlobal; Guilford, CT, USA) supplemented with $10 \%$ serum protein substitute (SPS, Cooper/Sage; Pasadena, CA, USA). Embryos were cultured at $37^{\circ} \mathrm{C}$ with $6 \% \mathrm{CO}_{2}$ in air until Day 6 .

ICMs from mouse embryos were isolated by immunosurgery [21], micro-dissection [22] or laser with microdissection [23]. Zonae were removed from any unhatched blastocysts using acid tyrodes solution. For immunosurgical isolation, zona free blastocysts were incubated with $20 \%$ rat anti-mouse serum for $1 \mathrm{~h}$ followed by $1 \mathrm{~h}$ incubation with $20 \%$ guinea pig complement. Lysed trophectodermal cells were removed from ICMs by repeated pipetting with finely drawn glass micropipettes. For both of the micro-dissection techniques, zona-free blastocysts were first plated and allowed to attach to the dish. After $48 \mathrm{~h}$, the ICM outgrowth was either micro- dissected free from surrounding trophectodermal cells or treated first with laser to destroy any residual trophectoderm cells before microdissection. Isolated ICMs were either cultured as fresh controls or cryopreserved by vitrification.

\section{ICM vitrification/warming}

Vitrification of isolated ICMs was carried out using a two step equilibration protocol: (1) 7.5\% DMSO/7.5\% ethylene glycol (EG) for $2 \mathrm{~min}$, (2) $15 \% \mathrm{DMSO} / 15 \% \mathrm{EG}+10 \mu \mathrm{g} / \mathrm{ml}$ Ficoll $+0.65 \mathrm{~mol} / \mathrm{L}$ sucrose for $45 \mathrm{~s}$. The basal medium used to constitute vitrification solutions was Global Blast medium with $20 \%$ SPS. After the final equilibration step, individual ICMs were loaded on to the vitrification carrier and immersed in liquid nitrogen (LN2). In this study we tested two different carrier systems; the cryoloop (Hampton Research; Laguna, CA, USA) and the HSV straw (MidAtlantic Diagnostics; Laurrel, NJ, USA). The cryoloop is a microscopic nylon loop measuring $\sim 1.0 \mathrm{~mm}$ in diameter. For cryoloop vitrification, the ICM was loaded on to a thin film of fluid applied to the loop, before plunging into a vial containing LN2. The HSV straw consists of a capillary tube with a cut out region, creating a narrow gutter and an outer straw. The ICM was loaded on to the gutter, towards the open edge. The outer straw was then drawn over it and sealed to create a closed system. The entire unit was then stored in LN2.

Warming of vitrified embryos was performed at $37^{\circ} \mathrm{C}$. The cryoloop or HSV straw was immersed directly in basal culture medium containing $0.25 \mathrm{M}$ sucrose. The ICM cells displaced from the carriers were readily visualized using the dissecting scope. After $2 \mathrm{~min}$, recovered ICMs were moved to the second solution containing $0.125 \mathrm{M}$ sucrose for $3 \mathrm{~min}$ and then placed in culture.

\section{ICM culture}

Embryonic stem cell medium (ESC-sure DMEM; Applied Stem Cell, Sunnyvale, CA, USA) supplemented with $20 \%$ FBS, $200 \mathrm{mM}$ non-essential amino acids, $100 \mathrm{U} / \mathrm{ml}$ penicillin, $10 \mu \mathrm{g} / \mathrm{ml}$ streptomycin, $100 \mathrm{mM}$ sodium pyruvate and $\beta$ mercaptoethanol and $10 \mathrm{ng} / \mathrm{ml}$ of mouse leukemia inhibitory factor (LIF; Chemicon; Temecula, CA, USA) was used for culture of ICMs. ICM-derived ES cells were cultivated on inactivated mouse embryonic feeder layers (MEF). MEF cells were purchased (Applied Stem Cell; Sunnyvale, CA, USA) and prepared as per manufacturer's instructions. Alternatively, ICMs were grown without feeder cells on $0.1 \%$ gelatin coated eight or 16 well chamber slides with $25 \%$ MEF conditioned medium $/ 75 \%$ ESC complete medium. Cultures were monitored for attachment and morphology. Within 2-3 days of seeding, dome-like colonies developed. These cell clumps were individually picked off of the culture surface and disaggregated by treatment with trypsin: EDTA solution for 3-5 min at room temperature. Dissociated cells were re-seeded in to new dishes. Colonies were passaged every 3-6 days, depending on colony growth. Culture medium was exchanged every $48 \mathrm{~h}$.

\section{Stem cell characterization}

ICMs and ICM-derived ESC colonies were tested during the culture interval for expression of stem cell specific markers; SSEA-1, Oct-4 and SOX-2 and alkaline phospatase(AP) activity using the mouse ES/iPS cell characteriza- 
tion kit (Applied Stem Cell, Sunnyvale, CA, USA). Cell fixation and permeabilization was carried out using kit reagents as per manufacturer's instructions. After blocking, cells were incubated with primary antibody against SSEA1 , Sox- 2 or Oct- 4 overnight at $4^{\circ} \mathrm{C}$. Cells were subsequently washed twice with PBS and incubated with corresponding secondary antibodies conjugated with Alexa Fluor 594 for $1 \mathrm{~h}$ at room temperature. Cell nuclei were counterstained with DAPI for $10 \mathrm{~min}$. Samples were then washed and mounted on slides for further analysis. Immunoflourescent staining was visualized using confocal laser microscopy and optical sectioning with image analysis software. Alkaline phospatase (AP) staining was performed by incubating fixed cells with AP test solution (provided in kit) for $2 \mathrm{~h}$ at room temperature. AP activity was detected by light microscopy with phase-contrast optics. AP positive cells from ICMs and ICM-derived colonies stained dark navy blue.

\section{Data analysis}

The main outcome parameters measured were ICM survival, recovery and ability to attach within $24 \mathrm{~h}$ of warming. Differences between carriers were analyzed using Fishers exact test. $P$ values of $<0.05$ were considered significant.

\section{Results}

Isolated ICMs were easily vitrified using a two step ethylene-glycol/DMSO protocol. The post-warming survival rate was $100 \%$ (78/78). After plating, $95 \%$ (74/78) of ICMs were able to attach to MEF feeder layers and proliferate in culture. This was similar to the $95 \%$ attachment rate observed with non-vitrified control ICMs after $24 \mathrm{~h}$ of culture. Cryopreserved ICMs exhibited similar proliferation patterns as fresh control ICM's and could be passaged and expanded.

Figure 1 depicts the morphology of vitrified-warmed ICMs and the rapid increase in ICM outgrowth within $72 \mathrm{~h}$ of plating. Morphologically the cells displayed characteristics typical of pluripotent stem cells $[3,16]$ i.e. high ratio of nucleus to cytoplasm and prominent nucleoli. ICM derived colonies were tight and compact with distinct borders. Alkaline phosphatase activity was also high in the ICM-derived cells, another indication of stem cell origin (Fig. 1F). Immunocytochemical analysis further confirmed that ICM-derived ES-like cells from both fresh and vitrified ICMs expressed markers characteristic of pluripotent stem cells. Colonies were positive for SSEA-1, Sox-2 and Oct-4 (Fig. 2).

Approximately 5-7 days after the first passage, numerous ESC-like colonies could be seen. Colony diameter was observed to increase during this culture interval. Diameters ranged from $50-100 \mu \mathrm{m}$ in small colonies, $120-160 \mu \mathrm{m}$ in medium colonies and over $>180 \mu \mathrm{m}$ in the larger colonies. Cultures were trypsinized and re-plated when most colonies fell in the mid-size range. Colonies could be dissociated in to individual cells and re-seeded on to fresh MEF feeder layers. ESC-like colonies were once again established. To date the embryonic stem cell characteristics and colonyforming ability of the vitrified-warmed ICM cells have been maintained through three passages and up to 16 days in culture. We saw no indication of premature differentiation in the vitrified-warmed ICMs during the 16 days of culture. Oct-4 expression increased with time in culture (Fig. 2E).

Table 1 compares outcomes with the two vitrification carriers. No statistical difference was found in survival, recovery or plating efficiency between the two carriers. Both carriers proved to be effective and efficient systems for ICM vitrification. The one distinct advantage of the HSV straw was that it allowed aseptic vitrification with no direct contact between ICM cells and LN2. ICM-derived ES cells from both carriers retained their pluripotency and stem cell characteristics for the 16 day culture duration tested.

Separation of the ICM from the whole blastocyst is an important step if ICM banking is to be successfully applied. To this end we tried three different techniques for ICM isolation but none appeared to influence overall survival after warming or subsequent retention of ES phenotype during culture. Survival and attachment of cryopreserved ICMs was $85 \%$ (6/7) with immunosurgically isolated ICMs, as compared to $92 \%(47 / 51)$ and $100 \%(21 / 21)$ with the micro-dissection or micro-dissection/laser ablation technique, respectively. The immunosurgical method involved lysis of trophectodermal cells surrounding the ICM and thus required more hands-on manipulation of the embryo, as compared to the two micro-dissection methods. With the two microdissection methods, the ICM cluster was distinctly larger, owing to the additional growth time in vitro before actual ICM isolation. We observed that laser ablation decreased residual contamination of ICMs with trophectodermal cells before vitrification. ICM-derived stem cell populations were evident and enriched with each cell passage, regardless of initial amount of trophectodermal cells contamination.

\section{Discussion}

Establishment of stable pluripotent stem cell lines from embryos is a fairly labor-intensive process, involving numerous cell passages. The efficiency of stem cell derivation from the ICM of human embryos is between $30 \%$ and $50 \%$, depending on characteristics of the ICM [24]. 

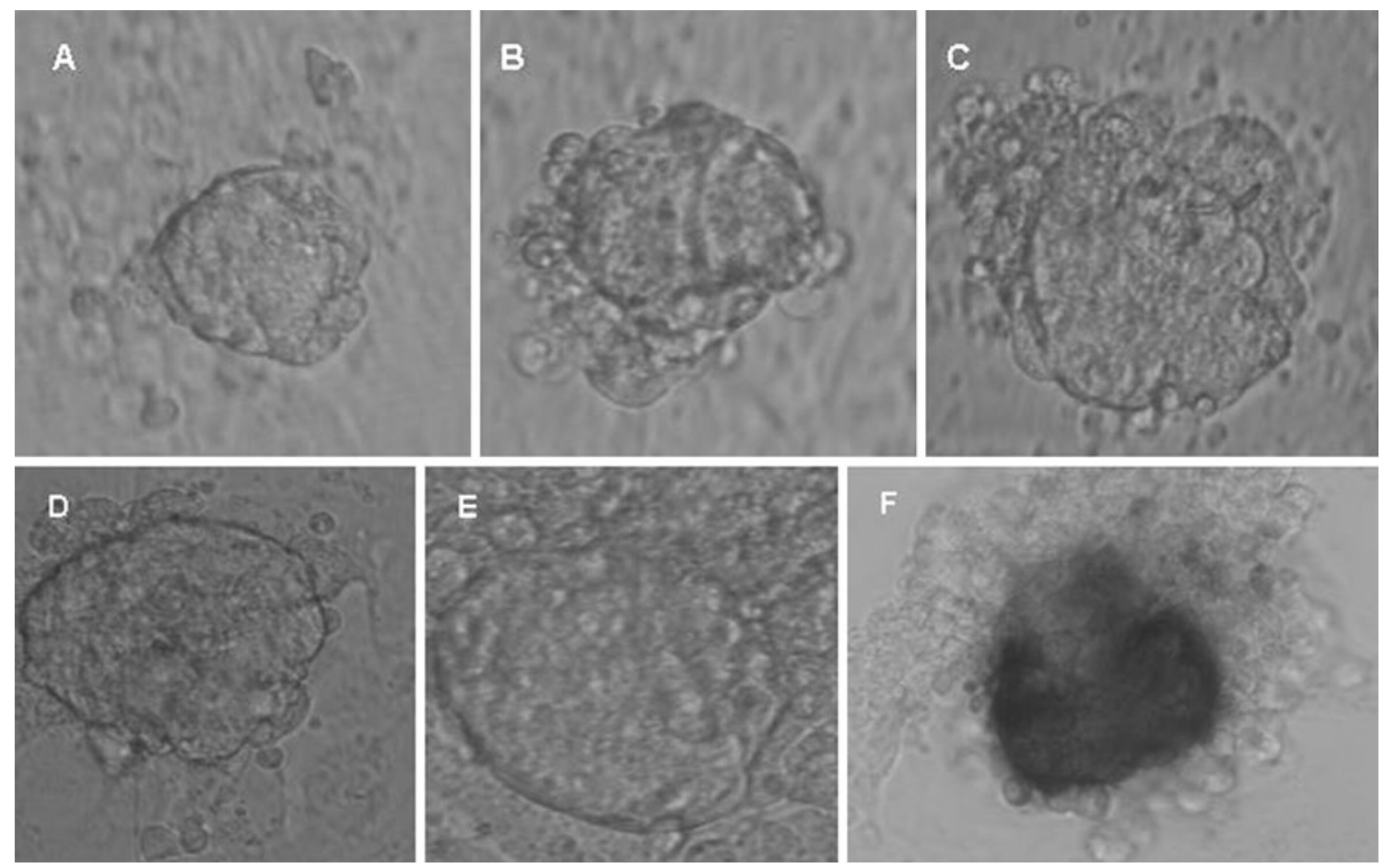

Fig. 1 ICMs were isolated from mouse blastocysts. (A) Fresh ICM before vitrification. (B-E) Morphology of vitrified - warmed ICMs after plating on MEF feeder layer. (B) 3 hours after warming (C) 24 hours
(D) 48 hours (E) 72 hours. (F) Dome-like ICM outgrowth staining positive for alkaline phosphatase. Trophectodermal and MEF cells adjacent to ICM were negative for AP
Vitrification of isolated ICMs is a novel approach for preservation of the "stem cell source" material, without first establishing an ESC line. This may be especially valuable for human ESC banking, eliminating the ethical complications of viable human embryos being kept in long term storage for future stem cell derivation. The current work represents the first attempt to cryopreserve isolated ICMs.

The cryopreservation of the small number of cells comprising the ICM is technically challenging. Current studies with embryos indicate that cryopreservation by vitrification may result in higher cell survival rates than with traditional slow cooling $[19,20]$. Reubinoff et al. [16] successfully applied vitrification to human embryonic cell lines HES1 and HES2 in an open pulled straw. Vitrification resulted in $100 \%$ recovery of ES clumps, subsequent attachment and colony formation. With slow cooling, they noted that only $70 \%$ of ES cell clumps were recovered after thawing and only $16 \%$ attached. Moreover, developing colonies were undersized and only a minority retained their pluripotent stem cell characteristics. Higher attachment and recovery rates after vitrification as compared to slow cooling were also reported by Li et al. [18]. Richards et al. [17] also observed higher post-thaw ES cell differentiation and cell death with the conventional slow freezing method as compared to vitrification in either open pulled straws or sealed straws [17]. These published data provided the rationale for applying vitrification method- ology to ICM cryopreservation. The scope of this investigation was to demonstrate the feasibility of ICM vitrification in a safe and effective manner and to provide evidence that the pluripotency of ICM cells was retained for several passages.

Vitrification requires the use of high concentrations of CPAs and ultra-rapid reduction in temperature to minimize the toxicity of cryoprotectant agents. To achieve this, special vessels or carriers are used that permit loading of cells in volumes of $<2 \mathrm{ul}$. The type of carrier can affect the rate of cooling. Direct exposure of the cellular material to LN2 as with the cryoloop results in cooling rates of close to $-20,000^{\circ} \mathrm{C} / \mathrm{min}$ [11]. In contrast, with closed sealed systems like the HSV straw, no direct contact is made with LN2 and the insulating effect of the outer sheath may reduce the cooling rate. The current data however establish that with either the open cryoloop or closed HSV carrier, a sufficiently high rate of temperature reduction was achieved to ensure ICM stem cell survival and capacity to propagate as pluripotent stem cell colonies. Concerns about crosscontamination in LN2 storage containers [25] may however make the closed HSV system more practical for long term storage of ICMs.

All of the ICMs in this investigation were isolated from blastocysts derived from frozen one-cell mouse embryos. The fact that ICMs from embryos that had already been cryopreserved once could survive a second cryopreservaton 

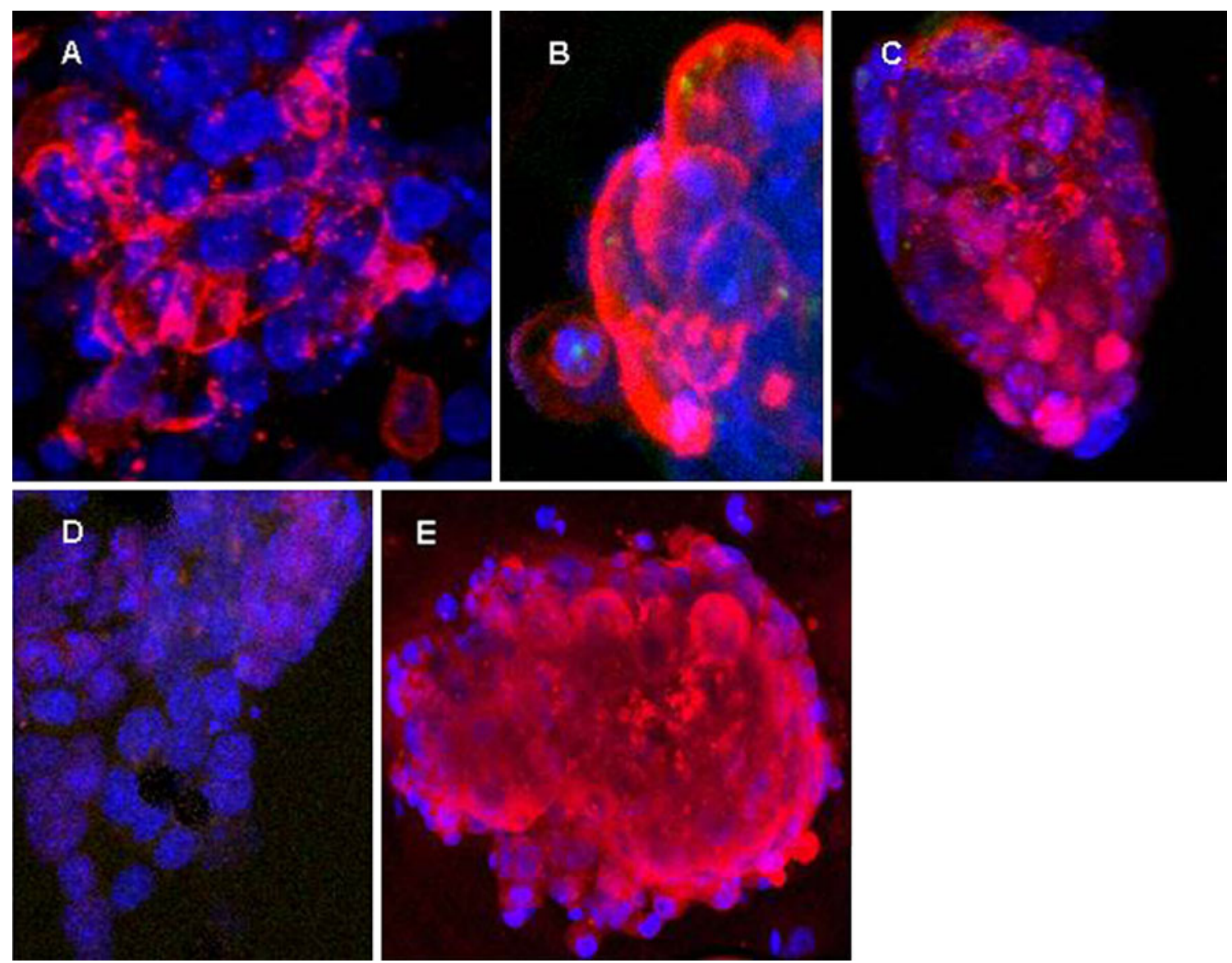

Fig. 2 Expression and localization of stem cell specific markers in vitrified-warmed ICMs after 48 hours in culture. ICMs were tested for expression of SSEA-1, Sox-2 and Oct-4 using immunoflouresecent staining. Cells were imaged using confocal laser microscopy. (A) ICM stained with SSEA 1 (red signal) and DAPI (blue signal). Staining is detected primarily on ICM cell surface. (B) Enlarged image of ICM cells stained with SSEA-1. (C) Sox-2 staining (red), detected in both nucleus and cytoplasm. (D) Oct-4 staining (red), mostly in the nucleus. MEF and any residual trophectodermal cells were negative for stem cell markers. (E) Oct-4 expression on Day 16 of culture procedure attests to the effectiveness of our vitrification technique. Warmed ICMs showed little indication of cellular damage and had high plating efficiency. Regardless of the initial method of ICM isolation, stem cell characteristics were retained by ICMs through at least three cell passages and 16 days of culture. Oct-4 is highly expressed in ES cells, and its expression is down regulated when cells differentiate [26]. Increased expression of this marker along with continued expression of SSEA-1 and Sox 2 are all indicative of ICM-derived cells generating pluripotent stem cells in culture.

Stem cell research holds great promise for the treatment of numerous diseases and for advancing the field of regenerative medicine. The demand for human embryonic stem cells is expected to increase as ES cells and derived tissue are used in therapeutic trials. Currently from 64 ES cell lines available from NIH registry, only one cell line, H1 has been approved for clinical trials [27]. Clearly, additional therapeutic grade stem cell lines derived in xeno-free culture systems and meeting stringent GMP standards will ultimately be needed. The source material for deriving such cell lines comes from embryos derived from in vitro fertilization. Cryopreservaton and storage of embryonic stem cells may be more socially acceptable than establishing banks of embryos exclusively for the purpose of future embryonic stem cell derivation. Currently, there are nearly 400,000 IVF-produced embryos in frozen storage in the United States alone [28]. Most of these will be used to treat

Table 1 Effect of carrier on ICM vitrification

\begin{tabular}{llll}
\hline & Recovery & Survival & Attachment \\
\hline Cryoloop(Open) & $21 / 21(100 \%)$ & $21 / 21(100 \%)$ & $20 / 21(95 \%)$ \\
HSV (Closed) & $57 / 58(98 \%)$ & $57 / 57(100 \%)$ & $54 / 57(95 \%)$ \\
\hline
\end{tabular}

*No significant differences were found between carriers for all parameters $(P>0.05)$ 
infertility, but approximately $2.8 \%$ are destined to be discarded. ICM banking is a novel approach to the problem of storing stem cell source material of varying genotypes without long term banking of the whole embryo and/or months of cell passaging of each donated embryo to derive a unique stem cell line. ICM karyotyping might also be possible before ICM vitrification.

Studies are underway to further expand the ESC colonies, derived from vitrified mouse ICMs to further document pluripotent functionality and retention of stem cell characteristics over extended in vitro culture intervals. Further validation of the concept of ICM banking requires the establishment of an ES cell line from a vitrified ICM that is capable of differentiating into the three embryonic germ cell lines both in vivo, after transplantation and in vitro thru directed differentiation using defined culture conditions. Mouse strain can affect the efficiency of establishing ES cell lines from isolated ICMs [29]. The strain used in this investigation is routinely used for IVF quality control. Long term studies are needed to determine its efficiency for establishing stable ES cell lines.

\section{Conclusions}

Our findings present a new approach to embryonic stem cell banking. Expansion of this work to human embryos is needed to determine if human ICMs are as easily vitrified and expanded as those in the mouse model. Timing of ICM isolation from human embryos can impact hESC derivation [24]. Optimization and simplification of ICM isolation protocols needs further investigation. Immunosurgical isolation methods for human ICM are less desirable due to the use of animal-derived reagents [27]. Laser ablation combined with micro-dissection and improved culture methodology for expansion of human ICM-derived stem cells without exposure to animal feeder layers or sera are still clearly needed to produce "clinical grade" stem cells suitable for therapeutic applications.

Open Access This article is distributed under the terms of the Creative Commons Attribution Noncommercial License which permits any noncommercial use, distribution, and reproduction in any medium, provided the original author(s) and source are credited.

\section{References}

1. Martin GR. Isolation of a pluripotent cell line from early mouse embryos cultured in medium conditioned by teratocarcinoma stem cells. Proc Natl Acad Sci USA. 1981;78:7634-8.

2. Evans MJ, Kaufman MH. Establishment in culture of pluripotential cells from mouse embryos. Nature. 1981;292:154-6.
3. Thomson JA, Itskovitz-Eldor J, Shapiro SS, Waknitz MA, Swiergiel JJ, Marshall VS, et al. Embryonic stem cell lines derived from human blastocysts. Science. 1998;282:1145-7.

4. Wobus AM. Potential of embryonic stem cells. Mol Aspects Med. 2001;22:149-64.

5. Smith AG. Embryo-derived stem cells: of mice and men. Annu Rev Cell Dev Biol. 2001;17:435-62.

6. Hunt CJ, Timmons PM. Cryopreservation of human embryonic stem cell lines. Methods Mol Biol. 2007;368:261-70.

7. Lane M, Schoolcraft WB, Gardner DK. Vitrification of mouse and human blastocysts using a novel cryoloop container-less technique. Fertil Steril. 1999;72:1073-8.

8. Liebermann J, Tucker MJ. Effect of carrier system on the yield of human oocytes and embryos as assessed by survival and developmental potential after vitrification. Reproduction. 2002;124:483-9.

9. Vanderzwalmen P, Bertin G, Debauche C, Standaert V, van Roosendaal E, Vandervorst M, et al. Births after vitrification at morula and blastocyst stages: effect of artificial reduction of the blastocoelic cavity before vitrification. Hum Reprod. 2002; 17:744-51.

10. Mukaida T, Nakamura S, Tomiyama T, Wada S, Oka C, Kasai M, et al. Vitrification of human blastocysts using cryoloops: clinical outcome of 223 cycles. Hum Reprod. 2003;18:384-91.

11. Kuwayama M, Vajta G, Ieda S, Kato O. Comparison of open and closed methods for vitrification of human embryos and the elimination of potential contamination. Reprod Biomed Online. 2005;11:608-14.

12. Desai N, Blackmon H, Szeptycki J, Goldfarb J. Cryoloop vitrification of human day 3 cleavage-stage embryos: postvitrification development, pregnancy outcomes and live births. Reprod Biomed Online. 2007;14:208-13.

13. Hong SW, Chung HM, Lim JM, Ko JJ, Yoon TK, Yee B, et al. Improved human oocyte development after vitrification: a comparison of thawing methods. Fertil Steril. 1999;72:142-6.

14. Kuleshova L, Gianaroli L, Magli C, Ferraretti A, Trounson A. Birth following vitrification of a small number of human oocytes: case report. Hum Reprod. 1999;14:3077-9.

15. Chen SU, Lien YR, Chao K, Lu HF, Ho HN, Yang YS. Cryopreservation of mature human oocytes by vitrification with ethylene glycol in straws. Fertil Steril. 2000;74:804-8.

16. Reubinoff BE, Pera MF, Vajta G, Trounson AO. Effective cryopreservation of human embryonic stem cells by the open pulled straw vitrification method. Hum Reprod. 2001;16:2187-94.

17. Richards M, Fong CY, Tan S, Chan WK, Bongso A. An efficient and safe xeno-free cryopreservation method for the storage of human embryonic stem cells. Stem Cells. 2004;22:779-89.

18. Li Y, Tan JC, Li LS. Comparison of three methods for cryopreservation of human embryonic stem cells. Fertil Steril. 2010;9(3):999-1005. Epub 2008 Dec 23.

19. Loutradi KE, Kolibianakis EM, Venetis CA, Papanikolaou EG, Pados G, Bontis I, et al. Cryopreservation of human embryos by vitrification or slow freezing: a systematic review and metaanalysis. Fertil Steril. 2008;90:186-93.

20. Abdelhafez FF, Desai N, Abou-Setta AM, Falcone T, Goldfarb J. Slow freezing, vitrification and ultra-rapid freezing of human embryos: a systematic review and meta-analysis. Reprod Biomed Online. 2010;20:209-22.

21. Solter D, Knowles BB. Immunosurgery of mouse blastocyst. Proc Natl Acad Sci USA. 1975;72:5099-102.

22. Kim HS, Oh SK, Park YB, Ahn HJ, Sung KC, Kang MJ, et al. Methods for derivation of human embryonic stem cells. Stem Cells. 2005;23:1228-33.

23. Turetsky T, Aizenman E, Gil Y, Weinberg N, Shufaro Y, Revel A, et al. Laser-assisted derivation of human embryonic stem cell lines from IVF embryos after preimplantation genetic diagnosis. Hum Reprod. 2008;23:46-53. 
24. Chen AE, Egli D, Niakan K, Deng J, Akutsu H, Yamaki M, et al. Optimal timing of inner cell mass isolation increases the efficiency of human embryonic stem cell derivation and allows generation of sibling cell lines. Cell Stem Cell. 2009;4:103-6.

25. Bielanski A, Nadin-Davis S, Sapp T, Lutze-Wallace C. Viral contamination of embryos cryopreserved in liquid nitrogen. Cryobiology. 2000;40:110-6.

26. Niwa H, Miyazaki J, Smith AG. Quantitative expression of Oct-3/ 4 defines differentiation, dedifferentiation or self-renewal of ES cells. Nat Genet. 2000;24:372-6.
27. Hasegawa K, Pomeroy JE, Pera MF. Current technology for the derivation of pluripotent stem cell lines from human embryos. Cell Stem Cell. 2010;6:521-31.

28. Yu J, Thomson J. Embryonic stem cells. In: In "Stem Cell Information" [WorldWide Website] Bethesda,MD: National Institutes of Health (NIH); U.S. Department of Health and Human Services; 2010.

29. Kawase E, Suemori H, Takahashi N, Okazaki K, Hashimoto K, Nakatsuji N. Strain difference in establishment of mouse embryonic stem (ES) cell lines. Int J Dev Biol. 1994;38:38590. 